\title{
Verification of a Leaf Litter Decomposition Model Based on Long-term Field Trials in Gongga Mountain, Qinghai-Tibetan Plateau, China
}

\section{Ronggui Tang}

State Key Laboratory of Subtropical Silviculture, Zhejiang A\&F University, Hangzhou, 311300, China Thomas H. DeLuca

State Key Laboratory of Subtropical Silviculture, Zhejiang A\&F University, Hangzhou, 311300, China Yanjiang Cai ( $\nabla$ yjcai@zafu.edu.cn )

State Key Laboratory of Subtropical Silviculture, Zhejiang A\&F University, Hangzhou, 311300, China

Shouqin Sun

Key Laboratory of Mountain Surface Processes and Ecological Regulation, Institute of Mountain Hazards and Environment, Chinese Academy of Sciences \& Ministry of Water Conservancy, Chengdu, 610049, China

Ji Luo

College of Forestry, Oregon State University, Corvallis, 97331, USA

\section{Manuscript}

Keywords: Decomposition rate, Vertical differentiation, Exponential model, C:N ratio, AIC

Posted Date: February 15th, 2021

DOI: https://doi.org/10.21203/rs.3.rs-173477/v1

License: (9) This work is licensed under a Creative Commons Attribution 4.0 International License. Read Full License 
1 Verification of a leaf litter decomposition model based on long-term

2 field trials in Gongga Mountain, Qinghai-Tibetan Plateau, China

3 Ronggui Tang ${ }^{a, b}$, Thomas H. DeLuca ${ }^{c}$, Yanjiang Cai ${ }^{a^{*}}$, Shouqin Sun $^{\mathrm{b}}$, Ji Luo $^{\mathrm{b}, *}$

4 a. State Key Laboratory of Subtropical Silviculture, Zhejiang A\&F University, Hangzhou, 311300 ,

$5 \quad$ China

6 b. Key Laboratory of Mountain Surface Processes and Ecological Regulation, Institute of Mountain Hazards and Environment, Chinese Academy of Sciences \& Ministry of Water Conservancy, Chengdu, 610049, China

c. College of Forestry, Oregon State University, Corvallis, 97331, USA

* Corresponding author

\section{Prof. Yanjiang Cai.}

E-mail address: yjcai@zafu.edu.cn

State Key Laboratory of Subtropical Silviculture, Zhejiang A\&F University, Hangzhou, 311300,

15 China

\section{Prof. Ji Luo.}

E-mail address: 1uoji@imde.ac.cn

Key Laboratory of Mountain Surface Processes and Ecological Regulation, Institute of Mountain

\section{R Tang}




\section{T DeLuca}

email: tom.deluca@oregonstate.edu

\section{S Sun}

email: shouqinsun@scu.edu.cn

\section{Abstract \\ Background and aims}

Although litter decomposition is a vital soil ecosystem process in forest ecosystems, most decomposition models are based on short-term decomposition experiments. Prediction of long-term decomposition dynamics using short-term decomposition models may lead to unreliable results. A leaf-litter decomposition model was evaluated and verified using a long-term field trial in Gongga Mountain, on the eastern flank of the Qinghai-Tibetan Plateau, China.

\section{Methods}

A 90-month experiment employing 360 broad-leaf litter (five species) samples were conducted using the litterbag method at three elevations (2250 m, $2780 \mathrm{~m}$ and $3000 \mathrm{~m}$ a.s.1.) in Gongga Mountain. The remaining litter mass was measured to fit a mathematical decomposition model by different exponential functions (two-, three-, four- and six-parameters) and akaike information criterion (AIC).

\section{Results}

The four-parameter model $\left(M_{t}=M_{f} \times \mathrm{e}^{-k f \times t}+M_{s} \times \mathrm{e}^{-k s \times t}\right)$ employed for each litter type among the four functions showed the highest $\mathrm{R}^{2}$ and lowest AIC value. The fast and slow decomposition rate constant $\left(k_{f}\right.$ and $k_{s}$ ) for a given litter at $2250 \mathrm{~m}$ was higher than that observed at $3000 \mathrm{~m}$.

\section{Conclusions}


48 These results indicated that the four-parameter exponential function (two-pool model) was recommended as a suitable decomposition model of long-term broadleaf litter decomposition at different elevations on Gongga Mountain.

51

\section{Keywords}




\section{Introduction}

Plant litter deposition and decomposition are the major pathways connecting above and belowground ecological processes. Litter decomposition is a key step in the mineralization and transformation of organic matter in ecosystems (Gessner et al. 2010; Wardle et al. 2004) and plays a critical role in terrestrial global carbon (C) cycle (Moore et al. 2004; Schimel 1995). Therefore, clarifying litter decomposition process and dynamics is important in the study of nutrient cycling, developing local, regional or global $\mathrm{C}$ budgets and assessing implications and impacts of global climate change (Zhou et al. 2008).

Previously, a short-term (less than three years) decomposition model using single-exponential function (2.4 section for the details) has been used to describe litter decomposition. Although this model yielded many insights into the temporal pattern in the early decomposition dynamics (Kaspari et al. 2008; Lehto et al. 2010; Montané et al. 2013; Moore et al. 1999; Shanks and Olson 1961; Zhou et al. 2008), the single-exponential decomposition curve was inadequate to reveal the later phases of litter decomposition due to the complexity of decomposition process. Therefore, long-term decomposition models (Adair et al. 2008; Preston et al. 2009a; Preston et al. 2009b) which divided litter into two- or three- pools (representing fast and slow decomposition) with three-, four- or six- parameters determined by the chemical composition was proposed for explaining decomposition dynamics in different periods (more details in 2.4 section). The labile or soluble fractions (e.g. sugars and amino acids) in litter decompose rapidly, while hemicellulose, lignified cellulose and lignin decompose slowly (Aber et al. 1990). Although single exponential function did not capture the initial rapid decomposition phase (Chen et al. 2002), it performed remarkably well for the most of the data from short-term experiments. However, long-term two- or three- pool models have not been verified in many locales because few long-term (more than 5 years) experiments have tracked the process from the fresh litter to the formation of highly decomposed components, leading to different litters being fit with the special models in different regions (Harmon et al. 2009). 
conducted to evaluate and verify an appropriate leaf litter of decomposition model. High mountain environments was highly sensitive to climatic and ecological variations and have been registered in several natural plant-soil systems (Orlandi et al. 2002). Gongga Mountain is located on the eastern flank of the Qinghai-Tibetan Plateau on the border of the secondary ladder of China. The plant-soil systems of different elevations (with different climatic gradients) on the eastern slope of Gongga Mountain could potentially be used to monitor climatic and ecological changes at the local and regional scale (Luo et al. 2015). Therefore, the study of long-term litter decomposition linking plantsoil systems in Gongga Mountain was particularly necessary.

Generally, a model with suitable parameters, higher R square and lower AIC value stand for a better fit. We therefore hypothesized that long-term leaf litter decomposition in Gongga Mountain would be most effectively fitted by two-pool model with four-parameter, with initial mass of each pool modified by different $\mathrm{C}$ components and the decomposition rate of each pool modified by different elevations (local climatic conditions). To investigate this hypothesis, we measured remaining litter mass and $\mathrm{C}, \mathrm{N}$ contents of the five-type of leaf litters in a 90-month field experiment at different elevations. The specific objectives of this study were to: (1) find a suitable statistical decomposition model for leaf litter by examining a series of mathematical functions; (2) determine the elevation and species influence on the litter decomposition rate constant on Gongga Mountain.

\section{Materials and methods}

Litterbag experiments

This study was conducted on sites at three unique elevations (2250, 2780 and $3000 \mathrm{~m})$ on Gongga Mountain, on the eastern edge of the Qinghai-Tibetan Plateau, China. The study was conducted from April 2007 to October 2014. The average annual air temperature and precipitation in each experimental site are shown in Table 1. Litterbags (length $\times$ width: $15 \mathrm{~cm} \times 15 \mathrm{~cm}$ ) were constructed by $1 \mathrm{~mm}^{2}$ nylon mesh. The litterbag of mesh size $1 \mathrm{~mm}^{2}$ could confine macrofauna (body width > 
$1142 \mathrm{~mm})$ and some mesofauna $(1.0 \sim 2.0 \mathrm{~mm})$ in soil to pass through the mesh. A dacron cloth on the

115 bottom of litterbag was used to prevent fine litter fragments produced during decomposition from

116 escaping from the mesh. However, we believe this mesh size takes into account litter decomposition

117 by partial mesofauna $(0.1 \sim 1 \mathrm{~mm})$ and all microfauna $(<0.1 \mathrm{~mm}$, nematodes, protozoa etc. $)$ in soil.

118 Although the litterbag method has some limitations (e.g. potential exclusion of some fauna) (Kurz-

119 Besson et al. 2005), it remains one of the simplest and most effective approach to assessing litter 120 decomposition (Wider and Lang 1982).

A total of 360 litterbags were employed to conduct the field experiment with only one type of litter in each bag, but given the diversity of litter types and elevations, we collected a total of 306 litterbags by the end of experiment (Figure 1). The experiment employed five types of broad-leaf litters including Lithocarpus cleistocarpus, Populus purdomii, Populus lasiocarpa, Betula utilis and Rhododendron faberi which were the dominant species at 2250, 2780 and $3000 \mathrm{~m}$ a.s.1., and were separately collected using a litter trap $(1 \mathrm{~m} \times 1 \mathrm{~m}$ frame consisting of a nylon mesh $)$ in September-October, 2006. After removing woody debris and small branches in the litter trap, all collected leaflitters was first air-dried and then oven dried to constant weight of $45^{\circ} \mathrm{C}$ and finally stored under a dark and dry condition until the experiment of field decomposition. three-elevation sites in April 2007 on three replicate plots (Figure 1). The litterbags were placed under $0-5 \mathrm{~cm}$ of Oi horizon in intimate contact with the underlying and overlying litter, where there were standing grasses and thick moss layers (Moore et al. 1999). A single bag of each litter from each field site was collected every 3-6 months during the first 1.5 years, and then once a year until the $90^{\text {th }}$ month. The samples were collected 6-12 times (some litterbags could not be found during sample collection). There were three replicates collected for each species and at each time. After collection, remaining litter mass from each litterbag was carefully transferred to a clean, dry envelope, dried to constant weight at $45^{\circ} \mathrm{C}$, weighed using an electronic balance $(0.01 \mathrm{~g})$ and finally stored in the zip-lock bag until analysis for total $\mathrm{C}$ and nitrogen $(\mathrm{N})$. 
144 The litter samples were ground to a fine powder and sieved through a $76 \mu \mathrm{m}$ sieve. The $\mathrm{C}$ and $\mathrm{N}$

145 contents of the powder were analyzed using the Elemental Analyzer (elementar vario MICRO cube,

146 Germany). The standard deviations for measurements of litter $\mathrm{C}$ and $\mathrm{N}$ were less than $0.3 \%$. Regret-

147 fully, hemicellulose, cellulose, lignin and ash contents of litters were not measured. Besides, the C

148 and $\mathrm{N}$ of collected some litters did not be measured due to limited mass for other analyses.

149

150

Litter decomposition models

The remaining mass rate was calculated by the following function:

$$
Y=\frac{M_{t}}{M_{0}}
$$

Where $Y$ is the remaining mass rate, $M_{0}$ is the initial dry litter mass; $M_{t}$ is the dry litter mass at time $t$.

The litter decomposition model is vital to predict $\mathrm{C}$ and nutrient turnover rates. Several studies have shown that the empirical short-term (0.5-3 years) model for litter decomposition can be quantified by the negative exponential function, and more details of derivation process are shown in the supporting information (Gholz et al. 2000; Kaspari et al. 2008; Olson 1963; Zhou et al. 2008):

$$
M_{t l}=M_{01} \times \mathrm{e}^{-k l \times t}
$$

Where $M_{t l}$ is the dry litter mass (g) at time $t$ (months), $t$ is time in months, $k_{l}$ is the decomposition rate constant $\left(\right.$ month $\left.^{-1}\right)$, and $M_{01}(100 \pm 5)$ is the initial dry litter mass (two-parameter model).

The second model used is a negative exponential with an asymptote (three-parameter model or twophase decomposition model) (Harmon et al. 2009). 
167 Where $M_{t 2}$ is the dry litter (g) mass at time $t$ (months), $M_{02}$ is the first phase with the initial easily

168 decomposed dry litter mass, $t$ is time in months, $k_{2}$ is the decomposition rate constant $\left(\right.$ month $\left.^{-1}\right)$,

$169 A_{02}$ is the second phase (asymptote) with completely stable dry litter mass. $M_{02}$ and $A_{02}$ sum to

170 close $100 \pm 5$. In other word, the $A_{02}$ fraction of initial litter that either does not decompose or is composed of new stable material that was formed during the decomposition process.

There is also a theoretical "long-term" litter decomposition model (four-parameter model or a dual negative exponential model) (Harmon et al. 2009)

$$
M_{f 03}+M_{s 03} \approx 100 \pm 5
$$

where $M_{t 3}$ is the fraction of remaining mass at time $t$ (months), $M_{f 03}$ is the initial mass of fast pool and $k_{f 3}$ is the decomposition rate constant of this fast pool, while $M_{s 03}$ is the initial mass of slow pool and $k_{s 3}$ is the decomposition rate constant of slow pool, and $t$ is time in months. In this model, these two different fractions (fast and slow pools) are considered to decompose simultaneously, each of which is controlled by its own decomposition rate constant.

Additionally, there is a three-pool model (six-parameter model or a ternary negative exponential model), with a rapidly decomposing labile pool (labile and soluble C, sugars and amino acids, $M_{f}$ 04), an intermediate pool (representing nonlignified cellulose $M_{m 04}$ ), and a recalcitrant pool (lignified cellulose or lignin contents $M_{s 04}$ ) (Adair et al. 2008).

$$
M_{t 4}=M_{f 04} \times \mathrm{e}^{-k f 4 \times t}+M_{m 04} \times \mathrm{e}^{-k m 4 \times t}+M_{s 04} \times \mathrm{e}^{-k s 4 \times t}
$$

$$
M_{f 04}+M_{m 04}+M_{s 04} \approx 100 \pm 5
$$


litter mass of each pool, and $k_{f 4}, k_{m 4}$ and $k s_{4}$ are the decomposition rate constant of three pools, respectively.

The mass-remaining data of five types of leaf-litter was fitted respectively using these four models by SigmaPlot 12.5 and the goodness of fit was determined by the determination coefficient $\left(\mathrm{R}^{2}\right), p$ value and the akaike information criterion (AIC) value (Adair et al. 2008). The AIC value of each model was calculated using a script (AICcmodavg) in R software (http://cran.r-project.org/). The AIC combines the Kullback Leibler-distance (a natural distance function from a "true" probability distribution to a "target" probability distribution) with maximum likelihood estimation by using likelihood to estimate the relative KL-distance among competing models. Generally, more parameters in a model would have a higher probability of fitting data. However, AIC value helped us avoid over-fitting and provided a quantitative assessment of different models (the lowest AIC value has the best data fitting and is closest to the unknown truth).

\section{Results}

Models based on exponential functions of different parameters

Despite after 90-month long decomposition, considerable litter mass remained in some cases at the end of experiment (Table 2). Same species e.g. P. purdomii showed a low remaining mass (12.03\%) at low elevation and a high one (51.46\%) at $3000 \mathrm{~m}$. Different species at the same elevation showed either a similar remaining mass (e.g., $51.46 \%$ for P. purdomii vs $51.06 \%$ for B. utilis) or a wide discrepancy in remaining mass (e.g., $47.73 \%$ for L. cleistocarpus vs $21.27 \%$ for Rh. Faberi).

The remaining mass of the five leaf litter types over time were fitted to equations based on the two-, three-, four-, six-parameter exponential function (Figure 2) and the details of parameters in each model are shown in Table 3. The four-parameter function (two-pool model) of each litter had the 
highest $\mathrm{R}^{2}$ and the lowest AIC value among the four types of models. The four- and six- parameter function in this study were factually the same model because they use the equal decomposition rate constant $k_{m}$ and $k_{s}$ in six- parameter function for each litter, $M_{f 04}=M_{f 03}, M_{m 04}+M_{m 04}=M_{s 03}$ and the same $\mathrm{R}^{2}$. The range of $M_{01}$ in the two-parameter exponential function was $83.41-5.36$ and most values were less than 90 . There was a wide range in $M_{02}$ in the three-parameter function with values of 37.01-84.48. Furthermore, the $M_{02}+A_{02}$ of four-type litters including L. cleistocarpus (2250 m), P. purdomii (2250 $\mathrm{m}$ and $2780 \mathrm{~m})$, B. utilis $(3000 \mathrm{~m})$ were less than 95 . However, the majority of $M_{f 04}$ and $M_{s 04}$ values in the four-parameter exponential function fell on 21.50-34.95 and 66.66-79.35, respectively. Moreover, the $M_{f 03}+M_{s 03}$ of each litter was within the range of $100 \pm 5$.

Comparison of decomposition rate constants

According to the four-parameter model, the order of fast decomposition rate constant $k_{f}$ for the different litters was as follows: P. purdomii $(0.4010)>$ B. utilis $(0.3017)>$ L. cleistocarpus $(0.2543)>$ Rh. Faberi $(0.1675)>$ P. lasiocarpa $(0.0832)$ at $2250 \mathrm{~m}$, and B. utilis $(0.2906)>$ P. purdomii

The initial C:N of P. purdomii (17.87, 18.57, 16.36 at the 2250,2780 and $3000 \mathrm{~m}$, respectively) and B. utilis (14.09, 16.90 at the 2250 and $3000 \mathrm{~m}$, respectively) litter was lower than that of L. cleistocarpus $(41.79,42.62$ at the 2250 and $3000 \mathrm{~m}$, respectively) and $R h$. Faberi $(47.57,43.60$ at the 2250 and $3000 \mathrm{~m}$, respectively) (Figure 4). Generally, the higher initial C:N of different litters, the lower $k_{f}$ of four-parameter model. 


\section{Discussion}

245 A better statistical decomposition model for leaf-litters in Gongga Mountain

246 Litter decomposition generally slows after the short-term, high initial mass-loss rate (Berg and

247 Ekbohm 1991). Non-structural polymeric carbohydrates and low-molecular-weight phenols are 248 quickly lost in early decomposition stages (Hättenschwiler et al. 2011; Hättenschwiler and Jørgen249 sen 2010), then decomposition slows as the lignin and cellulose are attacked in the later decompo250 sition stages (Fioretto et al. 2005; Hammel et al. 1997). Four-parameter of two-pool model showed 251 a better mathematical fitting based on the decomposition datasets of five-type broadleaf litter in 252 Gongga Mountain by assessing the lowest AIC value and the highest $\mathrm{R}^{2}$. Moreover, the sum (initial 253 mass) of the two $\left(M_{f}\right.$ and $\left.M_{s}\right)$ pools in this model also conformed to the model hypothesis $(100 \pm$ 2545 ), and the former and later proportion accounted for approximately $20 \sim 30 \%$ and $70 \sim 80 \%$. However, 255 other models did not fully meet the requirements of our fitting parameters, e.g. $M_{01} \neq 100 \pm 5, M_{02}$ $256+A_{02} \neq 100 \pm 5$. Therefore, we chose to focus on the four-parameter model below as its performance was fully similar to the six- parameter model.

260 Since different litters at the same elevation were exposed to similar climatic conditions, differences 261 of decomposition rates were mainly related to the chemical compositions of different litter types, 262 e.g., litter quality (C:N ratio, $\mathrm{N}$ contents etc.) (Adair et al. 2008; Cusack et al. 2009; Fioretto et al. 263 2005; Vitousek et al. 1994; Vivanco and Austin 2011). In this study, all C and partial N loss of 264 different species was strongly correlated with mass loss for leaf litter (Figure S2A-D), suggesting that there was a close linear relationship between $\mathrm{C}$ and $\mathrm{N}$ release and mass remaining. Furthermore,

266 there were large differences in leaf characteristics that relate to decomposition. The P. purdomii and 267 B. utilis have thin, soft leaves and have a lower C:N (14-16), whereas L. cleistocarpus and Rh. faberi 268 that have thick leathery leaves (keratinized epidermal cells) and have a higher C:N (41-47). The 
higher $k_{f}$ of P. purdomii and B. utilis indicated that the fast decomposition rate constant $\left(k_{f}\right)$ is probably be influenced by the $\mathrm{N}$ content of different leaf litters, whereas the higher $k_{s}$ of $L$. cleistocarpus and $R h$. faberi indicates that the $k_{s}$ is probably influenced by the different $\mathrm{C}$ component of litter. Our results are conform to three former hypotheses of the LIDET (Long-term Intersite Decomposition Experiment Team) dataset in which litter decomposition was tracked over a 120 month period (Adair et al. 2008).

There was a clear effect of elevations on the decomposition of individual litter types, with the lowest decomposition $k\left(k_{f}\right.$ and $\left.k_{s}\right)$ found at $3000 \mathrm{~m}$ and higher decomposition $k$ at $2250 \mathrm{~m}$ or 2780 m. Climatic conditions (temperature, precipitation etc.) at the three elevations were likely important drivers of these differences (Adair et al. 2008; Aerts 1997; Bontti et al. 2009; Couteaux et al. 1995; Liski et al. 2003; Moore et al. 1999; Moorhead et al. 1999; Seastedt et al. 1983; Silver and Miya 2001). Unfortunately, we did not specifically measure decomposer (e.g. microbial community changes and soil fauna) activity in the full decomposition experiment due to limited samples. The leading factors controlling the leaf litter decomposition rate were beyond the academic realm to influence prescriptions of global environmental policy (Bradford et al. 2016). Therefore, efforts to regulate decomposition rates needs to be done at local or regional scales. Some studies have identified precipitation as a preferred predictor of litter decomposition rates compared to temperature (Bontti et al. 2009; Cusack et al. 2009). Another elevation gradient study of litter decomposition in a Peruvian forest showed that temperature shifts influenced leaf decomposition rates (Salinas et al. 2011). The different factors dictating litter decomposition were attributed to different local-scale influences (Bradford et al. 2014). In this study, the mean annual temperature at $3000 \mathrm{~m}$ was lower than that of at $2250 \mathrm{~m}$, whereas the precipitation at $3000 \mathrm{~m}$ was higher than that of at $2250 \mathrm{~m}$. Although the precipitation of these two elevations was different, the surface soil $(0-5 \mathrm{~cm})$ moisture contents in these two sites were all over $200 \%$ (Figure 5) throughout the year in this area suggesting moisture was not a limiting factor during the experiment. Therefore, precipitation may not be the only critical factor in determining decomposition rates in this area. The highest value for the $k_{f}$ of $P$. purdomii appeared in $2780 \mathrm{~m}$, where both temperature and precipitation were not at their maximum 
or the minimum. Therefore, although the temperature also showed obvious differences at the various elevations, we emphasize that litter decomposition rates should represent both of these important climatic factors.

\section{Conclusion}

A long-term decomposition model of leaf litter in Gongga Mountain was verified by using a fourparameter exponential function (two-pool model was the better statistical model). Different decomposition rates of litter were likely related to the initial C:N of litter and local temperature and precipitation conditions. Long-term decomposition models of broad-leaf litter types in this area would provide a valuable contribution to our understanding of decomposition dynamics on the eastern edge of the Tibetan Platean.

\section{Acknowledgements}

This present work was supported by the National Key R\&D Program of China (No. 2017YFC0504900), the Natural Science Foundation of Zhejiang province (LQ20D010003), the Second Tibetan Plateau Scientific Expedition and Research Prgram (STEP, No. 2019QZKK0307), the National Natural Science Foundation of China (No. 41771062, 41473078, 41471416, 417710626), the National Key Research and Development Program of China (2016YFC0503305), the State Key Laboratory of Subtropical Silviculture, Zhejiang A\&F University (2034020087, ZY20180301 and ZY20180205).

\section{References}

Aber JD, Melillo JM, McClaugherty CA (1990) Predicting long-term patterns of mass loss, nitrogen 
dynamics, and soil organic matter formation from initial fine litter chemistry in temperate forest ecosystems. Canadian Journal of Botany 68: 2201-2208.

Adair EC, Parton WJ, Del Grosso SJ, Silver WL, Harmon ME, Hall SA, Burke IC, Hart SC (2008) Simple three - pool model accurately describes patterns of long - term litter decomposition in diverse climates. Global Change Biology 14: 2636-2660.

Aerts R (1997) Climate, leaf litter chemistry and leaf litter decomposition in terrestrial ecosystems: a triangular relationship. Oikos 79: 439-449.

Berg B, Ekbohm G (1991) Litter mass-loss rates and decomposition patterns in some needle and leaf litter types. Long-term decomposition in a Scots pine forest. VII. Canadian Journal of Botany 69: 1449-1456.

Bontti EE, Decant JP, Munson SM, Gathany MA, Przeszlowska A, Haddix ML, Owens S, Burke IC, Parton WJ, Harmon ME (2009) Litter decomposition in grasslands of central North America (US Great Plains). Global Change Biology 15: 1356-1363.

Bradford MA, Berg B, Maynard DS, Wieder WR, Wood SA (2016) Understanding the dominant controls on litter decomposition. Journal of Ecology 104: 229-238.

Bradford MA, Ii RJW, Baldrian P, Crowther TW, Maynard DS, Oldfield EE, Wieder WR, Wood SA, King JR (2014) Climate fails to predict wood decomposition at regional scales. Nature Climate Change 4: 625 .

Chen H, Harmon ME, Sexton J, Fasth B (2002) Fine-root decomposition and N dynamics in coniferous forests of the Pacific Northwest, USA. Canadian Journal of Forest Research 32: 320-331.

Couteaux M-M, Bottner P, Berg B (1995) Litter decomposition, climate and liter quality. Trends in Ecology \& Evolution 10: 63-66.

Cusack DF, Chou WW, Yang WH, Harmon ME, Silver WL (2009) Controls on long - term root and leaf litter decomposition in neotropical forests. Global Change Biology 15: 1339-1355.

Fioretto A, Di Nardo C, Papa S, Fuggi A (2005) Lignin and cellulose degradation and nitrogen dynamics during decomposition of three leaf litter species in a Mediterranean ecosystem. Soil Biology and Biochemistry 37: 1083-1091.

Gessner MO, Swan CM, Dang CK, McKie BG, Bardgett RD, Wall DH, Hättenschwiler S (2010) Diversity meets decomposition. Trends in ecology \& evolution 25: 372-380.

Gholz HL, Wedin DA, Smitherman SM, Harmon ME, Parton WJ (2000) Long - term dynamics of pine and hardwood litter in contrasting environments: toward a global model of decomposition. Global Change Biology 6: 751-765.

Hammel K, Cadish G, Giller K (1997) Driven by nature: Plant litter quality and decomposition. Driven by nature: Plant litter quality and decomposition. 
Harmon ME, Silver WL, Fasth B, Chen H, Burke IC, Parton WJ, Hart SC, Currie WS (2009) Long term patterns of mass loss during the decomposition of leaf and fine root litter: an intersite comparison. Global Change Biology 15: 1320-1338.

Hättenschwiler S, Coq S, Barantal S, Handa IT (2011) Leaf traits and decomposition in tropical rainforests: revisiting some commonly held views and towards a new hypothesis. New Phytologist 189: 950-965.

Hättenschwiler S, Jørgensen HB (2010) Carbon quality rather than stoichiometry controls litter decomposition in a tropical rain forest. Journal of Ecology 98: 754-763.

Kaspari M, Garcia MN, Harms KE, Santana M, Wright SJ, Yavitt JB (2008) Multiple nutrients limit litterfall and decomposition in a tropical forest. Ecology Letters 11: 35-43.

Kurz-Besson C, Coûteaux M-M, Thiéry JM, Berg B, Remacle J (2005) A comparison of litterbag and direct observation methods of Scots pine needle decomposition measurement. Soil Biology and Biochemistry $37: 2315-2318$.

Lehto T, Aphalo PJ, Saranpää P, Laakso T, Smolander A (2010) Decomposition and element concentrations of Norway spruce needle litter with differing B, N, or P status. Plant and soil 330: 225-238.

Liski J, Nissinen A, Erhard M, Taskinen O (2003) Climatic effects on litter decomposition from arctic tundra to tropical rainforest. Global Change Biology 9: 575-584.

Luo J, Tang R, Sun S, Yang D, She J, Yang P (2015) Lead Distribution and Possible Sources along Vertical Zone Spectrum of Typical Ecosystems in the Gongga Mountain, Eastern Tibetan Plateau. Atmospheric Environment 115: 132-140.

Montané F, Romanyà J, Rovira $\mathrm{P}$, Casals $\mathrm{P}$ (2013) Mixtures with grass litter may hasten shrub litter decomposition after shrub encroachment into mountain grasslands. Plant and soil 368: 459-469.

Moore JC, Berlow EL, Coleman DC, Ruiter PC, Dong Q, Hastings A, Johnson NC, McCann KS, Melville K, Morin PJ (2004) Detritus, trophic dynamics and biodiversity. Ecology letters 7: 584-600.

Moore T, Trofymow J, Taylor B, Prescott C, Camire C, Duschene L, Fyles J, Kozak L, Kranabetter M, Morrison I (1999) Litter decomposition rates in Canadian forests. Global Change Biology 5: 75-82.

Moorhead D, Currie W, Rastetter E, Parton W, Harmon M (1999) Climate and litter quality controls on decomposition: an analysis of modeling approaches. Global Biogeochemical Cycles 13: 575-589.

Olson JS (1963) Energy storage and the balance of producers and decomposers in ecological systems. Ecology 44: 322-331.

Orlandi M, Pelfini M, Pavan M, Santilli M, Colombini MP (2002) Heavy metals variations in some conifers in Valle d'Aosta (Western Italian Alps) from 1930 to 2000. Microchemical Journal 73: 237 244.

Preston CM, Nault JR, Trofymow J (2009a) Chemical changes during 6 years of decomposition of 11 
litters in some Canadian forest sites. Part 2. 13C abundance, solid-state 13C NMR spectroscopy and the meaning of "lignin". Ecosystems 12: 1078-1102.

Preston CM, Nault JR, Trofymow J, Smyth C, Group CW (2009b) Chemical changes during 6 years of decomposition of 11 litters in some Canadian forest sites. Part 1. Elemental composition, tannins, phenolics, and proximate fractions. Ecosystems 12: 1053-1077.

Salinas N, Malhi Y, Meir P, Silman M, Roman Cuesta R, Huaman J, Salinas D, Huaman V, Gibaja A, Mamani M (2011) The sensitivity of tropical leaf litter decomposition to temperature: results from a large - scale leaf translocation experiment along an elevation gradient in Peruvian forests. New phytologist 189: 967-977.

Schimel DS (1995) Terrestrial ecosystems and the carbon cycle. Global change biology 1: 77-91.

Seastedt T, Crossley D, Meentemeyer V, Waide J (1983) A two - year study of leaf litter decomposition as related to macroclimatic factors and microarthropod abundance in the southern Appalachians. Ecography 6: 11-16.

Shanks R, Olson J (1961) First-year breakdown of leaf litter in southern Appalachian forests. Science 134: 194-195.

Silver WL, Miya RK (2001) Global patterns in root decomposition: comparisons of climate and litter quality effects. Oecologia 129: 407-419.

Vitousek PM, Turner DR, Parton WJ, Sanford RL (1994) Litter decomposition on the Mauna Loa environmental matrix, Hawai'i: patterns, mechanisms, and models. Ecology: 418-429.

Vivanco L, Austin AT (2011) Nitrogen addition stimulates forest litter decomposition and disrupts species interactions in Patagonia, Argentina. Global Change Biology 17: 1963-1974.

Wardle DA, Bardgett RD, Klironomos JN, Setälä H, Van Der Putten WH, Wall DH (2004) Ecological linkages between aboveground and belowground biota. Science 304: 1629-1633.

Wider RK, Lang GE (1982) A critique of the analytical methods used in examining decomposition data obtained from litter bags. Ecology 63.

Wu Y-h, Li W, Zhou J, Cao Y (2013) Temperature and precipitation variations at two meteorological stations on eastern slope of Gongga Mountain, SW China in the past two decades. Journal of Mountain Science 10: 370-377.

Zhou G, Guan L, Wei X, Tang X, Liu S, Liu J, Zhang D, Yan J (2008) Factors influencing leaf litter decomposition: an intersite decomposition experiment across China. Plant and Soil 311: 61-72. 


\section{Tables}

424 Table 1. The location of litter decomposition study sites on the east flank of Gongga Mountain

\begin{tabular}{ccccc}
\hline Elevation $(\mathrm{m})$ & $\mathrm{E}$ & $\mathrm{N}$ & $\begin{array}{c}\text { Precipitation } \\
\left(\mathrm{mm} \mathrm{yr}{ }^{-1}\right)\end{array}$ & $\begin{array}{c}\text { Mean (air/soil) } \\
\text { Temperature }\left({ }^{\circ} \mathrm{C} \text { year }\right. \\
{ }^{-}\end{array}$ \\
\hline 2250 & $102^{\circ} 02^{\prime} 53.160^{\prime \prime}$ & $29^{\circ} 35^{\prime} 46.716^{\prime \prime}$ & 1440 & $8.7 / 11$ \\
2780 & $102^{\circ} 01^{\prime} 35.400^{\prime \prime}$ & $29^{\circ} 35^{\prime} 15.108^{\prime \prime}$ & 1760 & $6.6 / 8.6$ \\
3000 & $101^{\circ} 59^{\prime} 39.840^{\prime \prime}$ & $29^{\circ} 34^{\prime} 33.096^{\prime \prime}$ & 1937 & $5.7 / 7.6$ \\
\hline
\end{tabular}

425

426

427

428

429

430

431

432

Table 2. The mean final percent remaining mass at the end of the experiment for elevations and species

\begin{tabular}{|c|c|c|c|c|c|}
\hline & L. cleistocarpus & P. purdomii & Rh. faberi & B. utilis & P. lasiocarpa \\
\hline \multirow[t]{2}{*}{$2250 \mathrm{~m}$} & $15.04 \%$ & $12.03 \%$ & $13.60 \%$ & $47.30 \%$ & $11.06 \%$ \\
\hline & (90 months) & (90 months) & (54 months) & (30 months) & (78 months) \\
\hline \multirow[t]{2}{*}{$2780 \mathrm{~m}$} & & $41.97 \%$ & & & \\
\hline & & (78 months) & & & \\
\hline \multirow[t]{2}{*}{$3000 \mathrm{~m}$} & $47.73 \%$ & $51.46 \%$ & $21.27 \%$ & $51.06 \%$ & \\
\hline & (78 months) & (90 months) & (78 months) & (90 months) & \\
\hline
\end{tabular}

Note: precipitation and air/soil temperature in 2250 and $2780 \mathrm{~m}$ a.s.l. were calculated based on the linear variation of data at $1621 \mathrm{~m}$ and $3000 \mathrm{~m}$ a.s.l. meteorological station (Wu et al. 2013). The data in $3000 \mathrm{~m}$ a.s.l. was the mean value from 2007 to 2014 . 


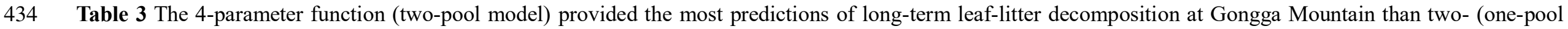
435 model), three (asymptote model), and six-(three-pool model) parameter functions.

\begin{tabular}{|c|c|c|c|c|c|c|c|c|c|c|c|}
\hline \multirow[t]{2}{*}{ Models } & \multirow[t]{2}{*}{ Parameters } & \multicolumn{2}{|c|}{ L. cleistocarpus } & \multicolumn{3}{|c|}{ P. purdomii } & \multicolumn{2}{|c|}{ Rh. faberi } & \multicolumn{2}{|c|}{ B. utilis } & \multirow{2}{*}{$\begin{array}{l}\text { P. lasiocarpa } \\
2250 \mathrm{~m}\end{array}$} \\
\hline & & $2250 \mathrm{~m}$ & $3000 \mathrm{~m}$ & $2250 \mathrm{~m}$ & $2780 \mathrm{~m}$ & $3000 \mathrm{~m}$ & $2250 \mathrm{~m}$ & $3000 \mathrm{~m}$ & $2250 \mathrm{~m}$ & $3000 \mathrm{~m}$ & \\
\hline \multirow[t]{5}{*}{$M_{t I}=M_{0 l} \times \mathrm{e}^{-k_{k x t}}$} & $M_{01}$ & 90.34 & 93.23 & 83.41 & 84.60 & 84.89 & 95.36 & 92.37 & 89.38 & 87.70 & 89.48 \\
\hline & $k_{1}$ & 0.0192 & 0.0092 & 0.0119 & 0.0097 & 0.0063 & 0.0373 & 0.0197 & 0.0266 & 0.0061 & 0.0175 \\
\hline & $R^{2}$ & 0.9565 & 0.9482 & 0.8761 & 0.8512 & 0.8227 & 0.9568 & 0.9501 & 0.8234 & 0.8461 & 0.8885 \\
\hline & $p$ & $<0.0001$ & $<0.0001$ & $<0.0001$ & 0.0001 & $<0.0001$ & 0.0001 & $<0.0001$ & 0.0125 & $<0.0001$ & $<0.0001$ \\
\hline & $A I C$ & 68.93 & 51.39 & 87.92 & 71.16 & 82.66 & 51.08 & 64.58 & 48.93 & 74.49 & 82.28 \\
\hline \multirow{4}{*}{$\begin{array}{l}M t 2=M o_{2} \times \mathrm{e}^{-k 2 k t} \\
+A_{02}\end{array}$} & $M_{02}$ & 76.85 & 50.51 & 51.34 & 45.13 & 38.47 & 84.48 & 73.81 & 49.70 & 37.01 & 62.08 \\
\hline & $k_{2}$ & 0.0312 & 0.0408 & 0.0503 & 0.0518 & 0.0645 & 0.0612 & 0.0457 & 0.1446 & 0.0383 & 0.0674 \\
\hline & $A_{02}$ & 16.61 & 48.29 & 40.22 & 46.99 & 56.66 & 15.77 & 25.28 & 49.53 & 55.79 & 38.33 \\
\hline & $M_{02}+A_{02}$ & 93.46 & 98.80 & 91.56 & 92.12 & 95.13 & 100.25 & 99.09 & 99.23 & 92.80 & 100.41 \\
\hline
\end{tabular}




\begin{tabular}{|c|c|c|c|c|c|c|c|c|c|c|c|}
\hline & $R^{2}$ & 0.9653 & 0.9892 & 0.9350 & 0.9171 & 0.9382 & 0.9731 & 0.9793 & 0.9691 & 0.8753 & 0.9931 \\
\hline & $p$ & $<0.0001$ & $<0.0001$ & $<0.0001$ & 0.0002 & $<0.0001$ & 0.0007 & $<0.0001$ & 0.0054 & 0.0002 & $<0.0001$ \\
\hline & $A I C$ & 68.67 & 40.89 & 89.92 & 67.31 & 69.75 & 49.76 & 53.17 & 45.89 & 74.18 & 82.72 \\
\hline & $M_{f 03}$ & 25.02 & 23.19 & 26.29 & 25.49 & 24.90 & 30.10 & 34.95 & 30.96 & 21.50 & 52.43 \\
\hline & $k_{f 3}$ & 0.2543 & 0.1085 & 0.4010 & 0.4225 & 0.2409 & 0.1675 & 0.1116 & 0.3017 & 0.2906 & 0.0832 \\
\hline & $M_{s 03}$ & 76.05 & 77.34 & 73.84 & 74.64 & 75.03 & 72.08 & 66.66 & 69.52 & 79.35 & 48.55 \\
\hline $\begin{array}{l}M_{t 3}=M_{f 03} \times \mathrm{e}^{-k f 3 k} \\
+M_{s 03} \times \mathrm{e}^{-k s 3 t}\end{array}$ & $k_{s 3}$ & 0.0154 & 0.006 & 0.009 & 0.007 & 0.0041 & 0.0261 & 0.0126 & 0.0124 & 0.0043 & 0.0039 \\
\hline & $M_{f 03}+M_{s 03}$ & 101.07 & 100.53 & 100.13 & 100.13 & 99.93 & 102.18 & 101.61 & 100.48 & 100.85 & 100.98 \\
\hline & $R^{2}$ & 0.9879 & 0.9972 & 0.9957 & 0.9916 & 0.9967 & 0.9799 & 0.9877 & 0.9864 & 0.9752 & 0.9944 \\
\hline & $p$ & $<0.0001$ & $<0.0001$ & $<0.0001$ & $<0.0001$ & $<0.0001$ & 0.0048 & $<0.0001$ & 0.0203 & $<0.0001$ & $<0.0001$ \\
\hline & $A I C$ & 60.17 & 31.97 & 42.46 & 46.41 & 46.85 & 49.73 & 51.52 & 45.30 & 52.56 & 79.20 \\
\hline & $M_{f 04}$ & 25.02 & 23.19 & 25.99 & 25.49 & 24.90 & 30.10 & 34.95 & 30.96 & 21.50 & 52.43 \\
\hline & $K_{f 4}$ & 0.2543 & 0.1085 & 0.4088 & 0.4225 & 0.2409 & 0.1675 & 0.1116 & 0.3017 & 0.2906 & 0.0832 \\
\hline
\end{tabular}




\begin{tabular}{|c|c|c|c|c|c|c|c|c|c|c|c|}
\hline & $M_{m 04}$ & 37.60 & 38.04 & 69.53 & 35.34 & 34.40 & 35.62 & 32.51 & 32.41 & 37.53 & 16.41 \\
\hline & $K_{m 4}$ & 0.0154 & 0.006 & 0.0099 & 0.007 & 0.0041 & 0.0261 & 0.0126 & 0.0124 & 0.0043 & 0.0039 \\
\hline & $M_{s 04}$ & 38.45 & 39.30 & 4.610 & 39.30 & 40.63 & 36.46 & 34.15 & 37.11 & 41.82 & 32.14 \\
\hline $\begin{array}{l}M t 4=M j 04 \times \mathrm{e}^{-\not f} \\
+M_{m 04} \times \mathrm{e}^{-604 \times t}\end{array}$ & $K_{s 4}$ & 0.0154 & 0.006 & 0.0258 & 0.007 & 0.0041 & 0.0261 & 0.0126 & 0.0124 & 0.0043 & 0.0039 \\
\hline$+M s 04 \times \mathrm{e}^{-k s 4 \times t}$ & $M_{f 04}+M_{m 04}+M_{m 04}$ & 101.07 & 100.53 & 100.13 & 100.13 & 99.93 & 102.18 & 101.61 & 100.48 & 100.85 & 100.98 \\
\hline & $R^{2}$ & 0.9879 & 0.9972 & 0.9957 & 0.9916 & 0.9967 & 0.9799 & 0.9877 & 0.9864 & 0.9752 & 0.9944 \\
\hline & $p$ & 0.0006 & 0.0069 & $<0.0001$ & $<0.0001$ & $<0.0001$ & 0.2385 & 0.0046 & $<0.0001$ & 0.0005 & 0.0001 \\
\hline & $A I C$ & l & l & l & l & l & 1 & l & 1 & l & l \\
\hline
\end{tabular}




\section{Figure captions}

Fig.1. Experimental sites, leaf types, times and total number of all collected litterbags at the end of decomposition experiment.

Fig.2. The comparison of different fitting models with respect to empiric litter decomposition rates collected at 2250, 2780 and $3000 \mathrm{~m}$ a.s.1. on the east slope of Gongga Mountain. Black solid line, red long-dash line and green dotted line were fitted by the two-, three- and four(six)- parameter models, respectively. The $\mathrm{R}^{2}$ and AIC value of each model was shown.

Fig.3. Comparison of decomposition rate constants in term of different species at different elevations based on the four-parameter model. The $k_{f}$ and $k_{s}$ stand for the fast and slow decomposition rate constant, respectively.

Fig.4. The initial C:N of litters (P. purdomii, L. cleistocarpus, B. utilis, Rh. faberi)

Fig.5. Plot A shows the soil moisture of different soil layer (A: 0-5 cm, B:5-10 cm, C:10-20 cm) in 


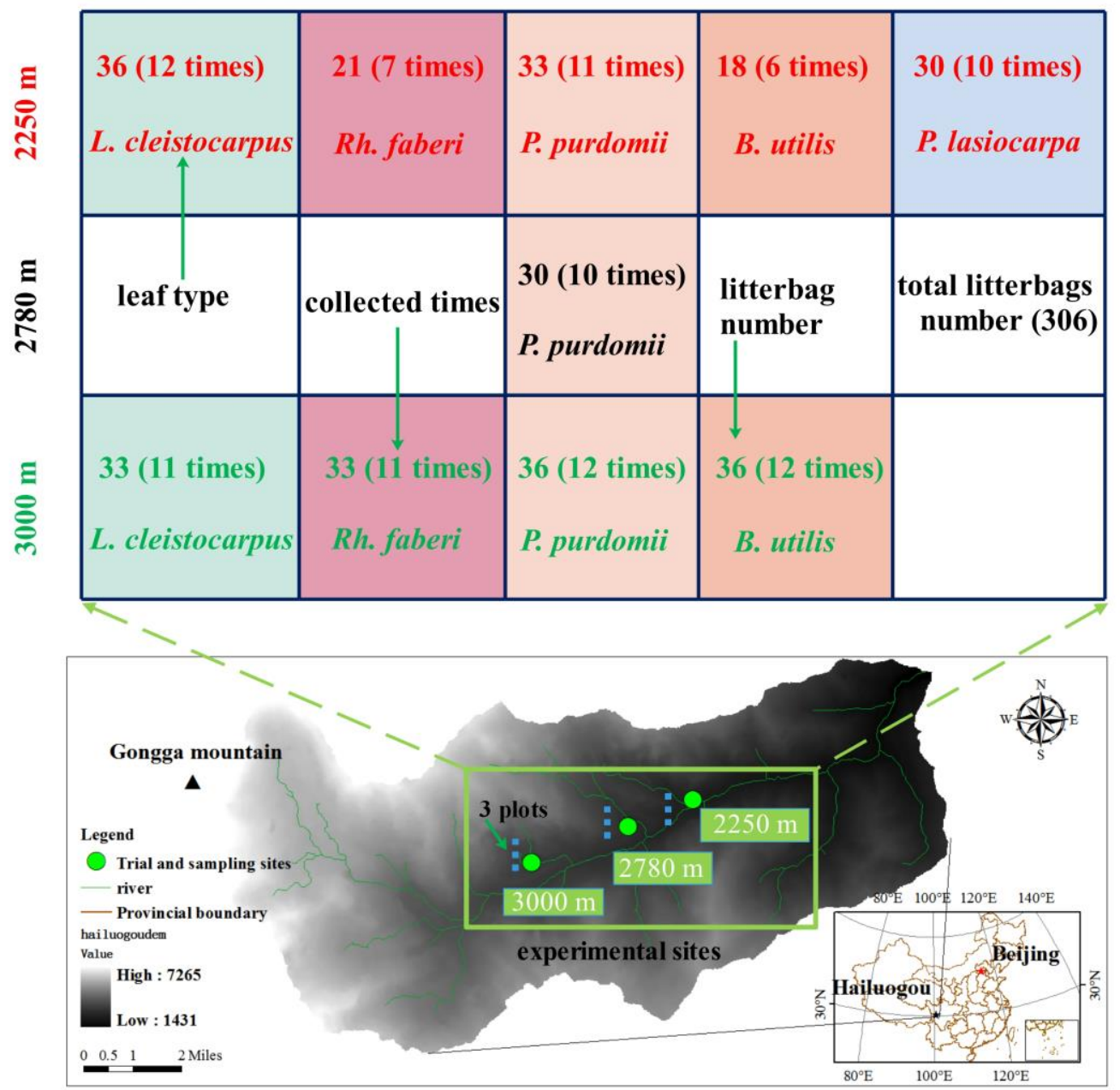

458 
(a)

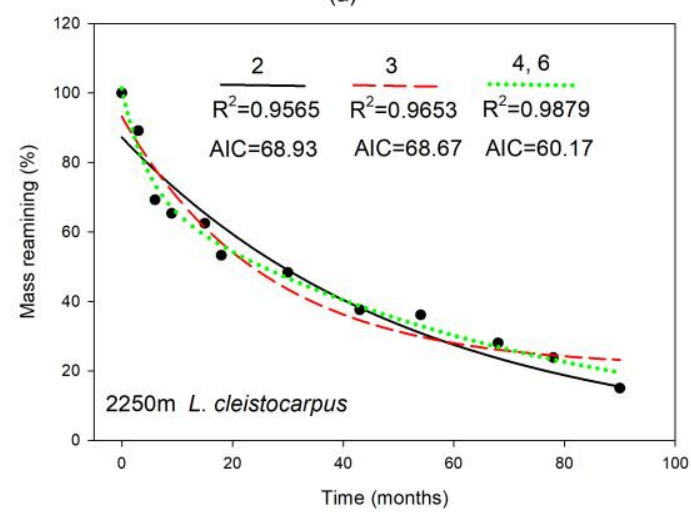

(b)

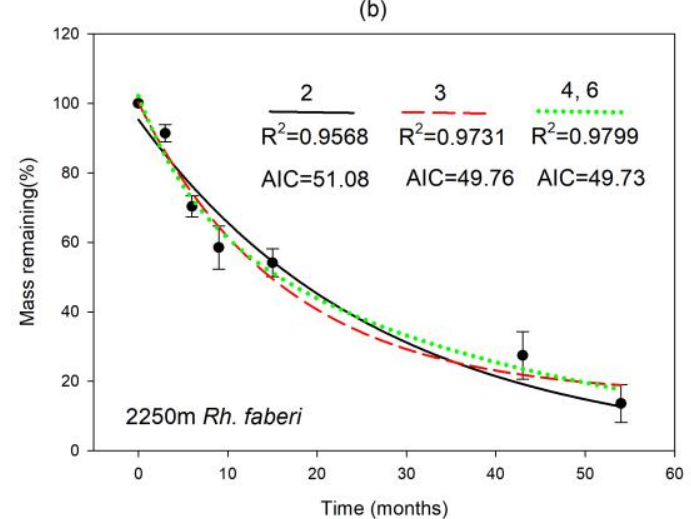

(c)

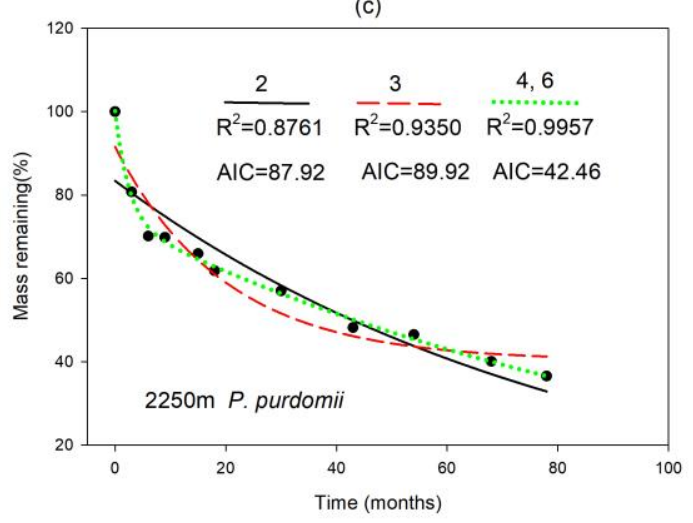

(d)

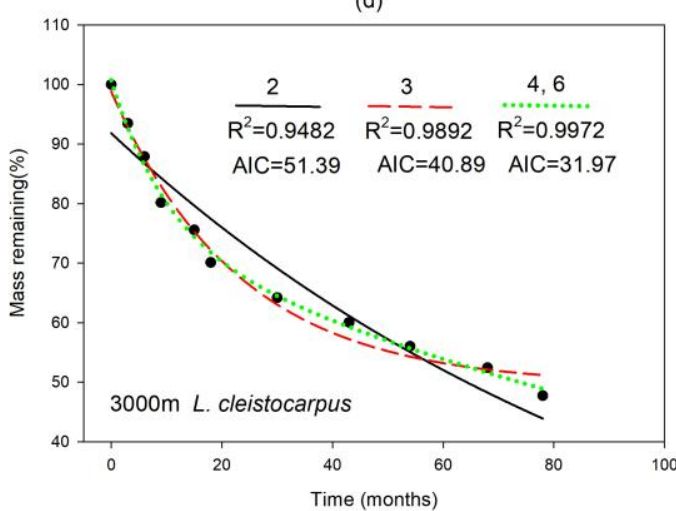

(e)

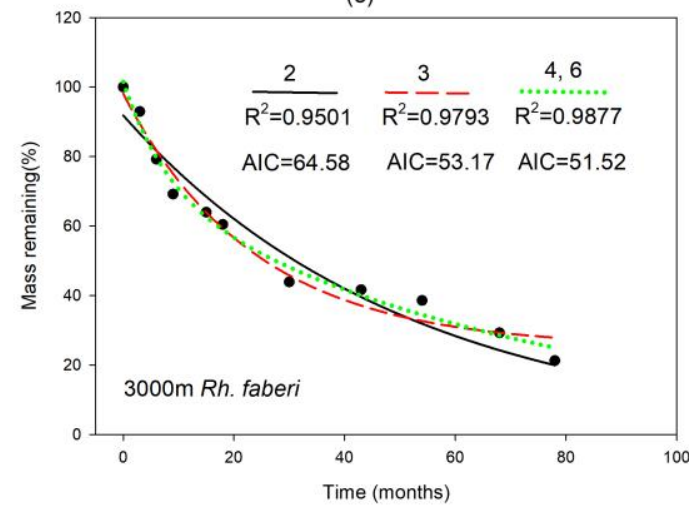

(f)

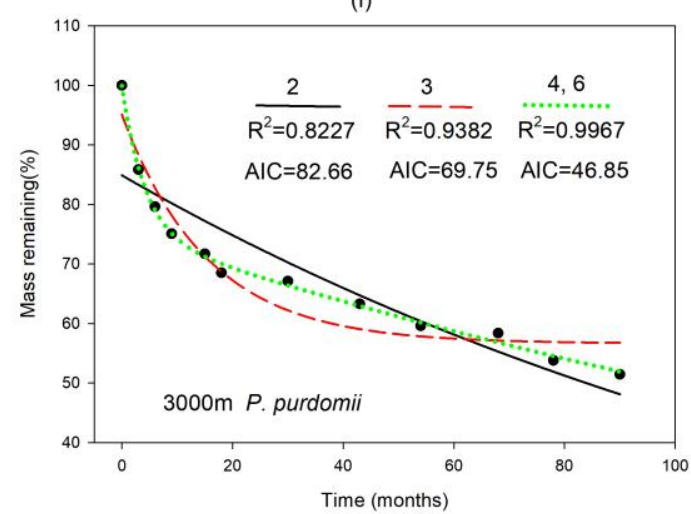


(g)

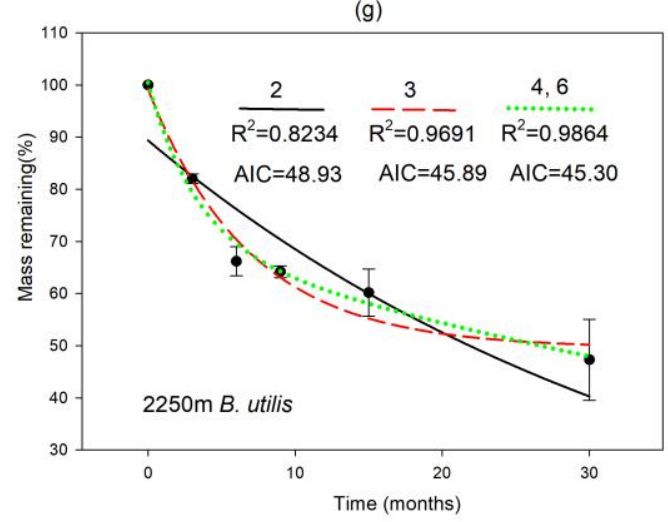

(h)

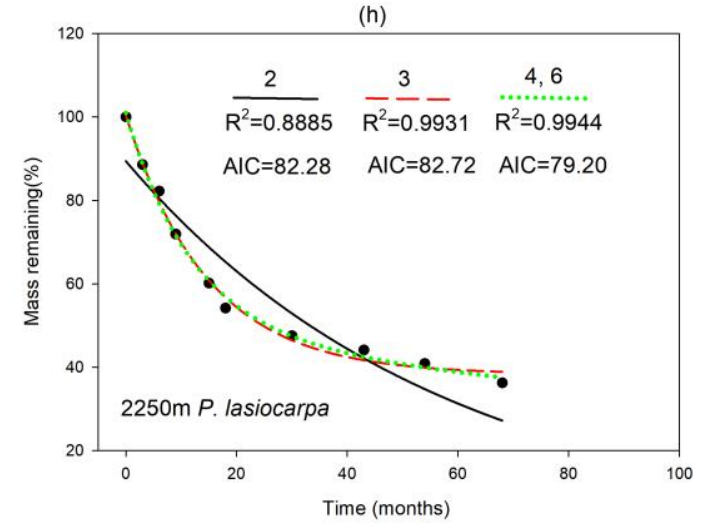

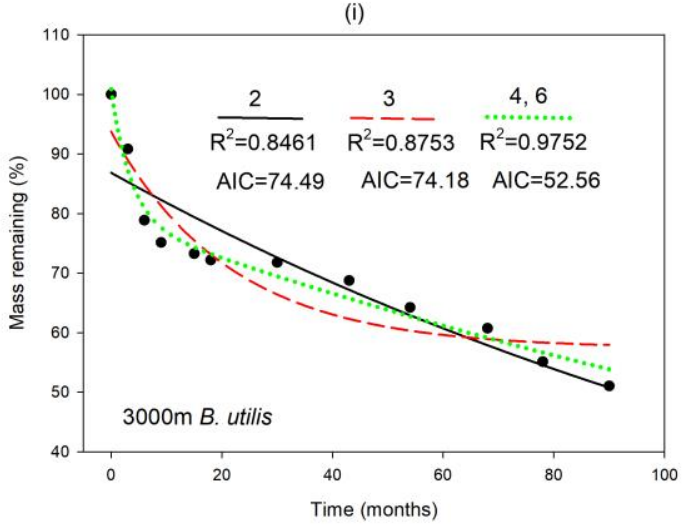

(j)

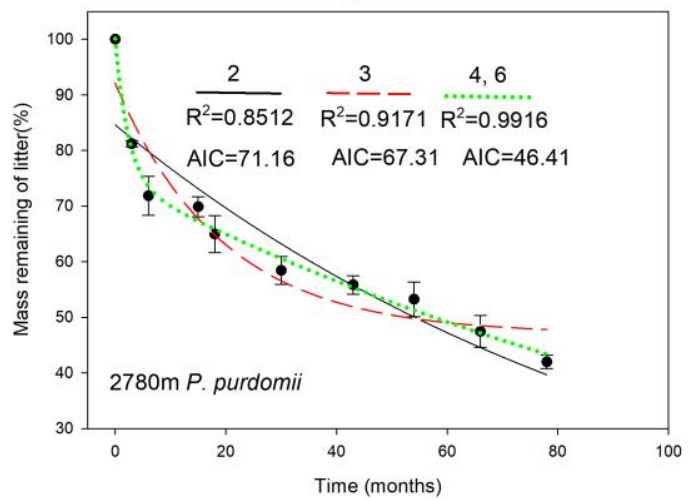


Fig.3

(A)

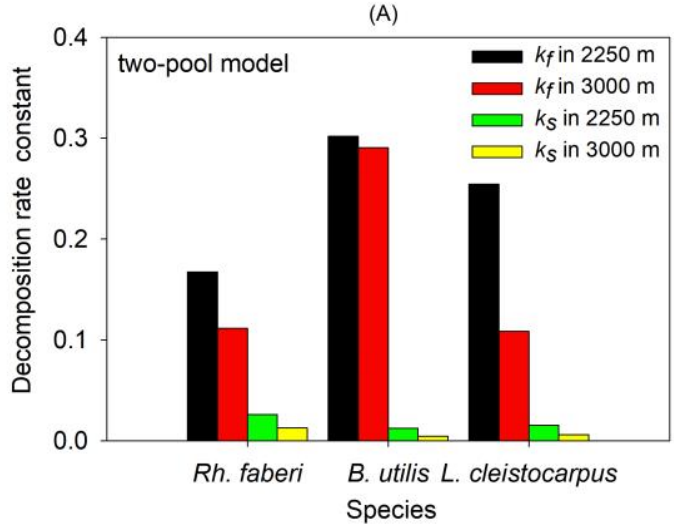

(B)

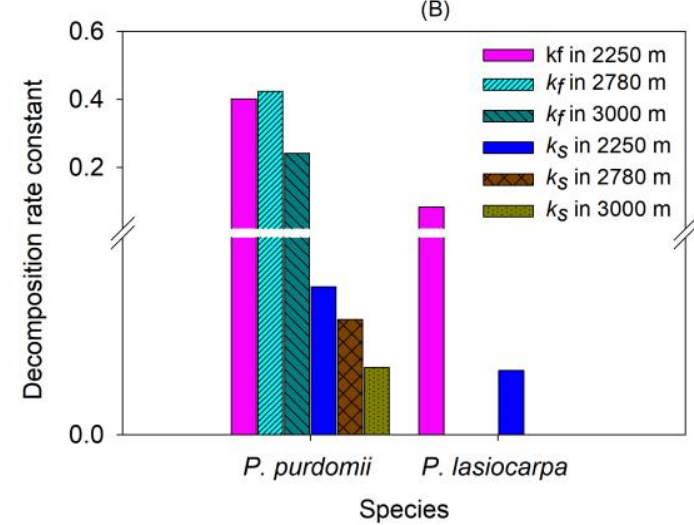

466

467 
Fig.4.

469

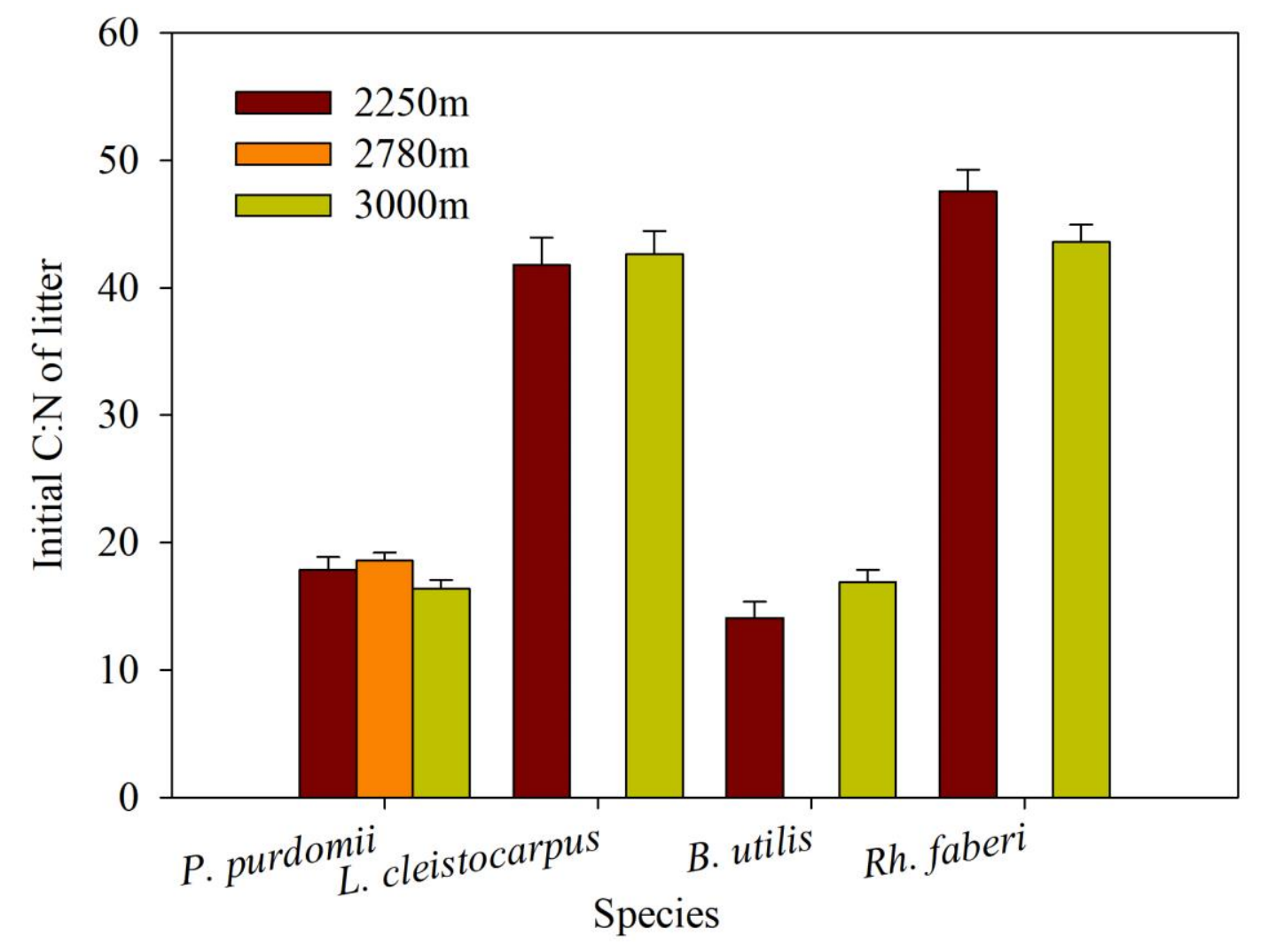

470 
Fig.5.

472
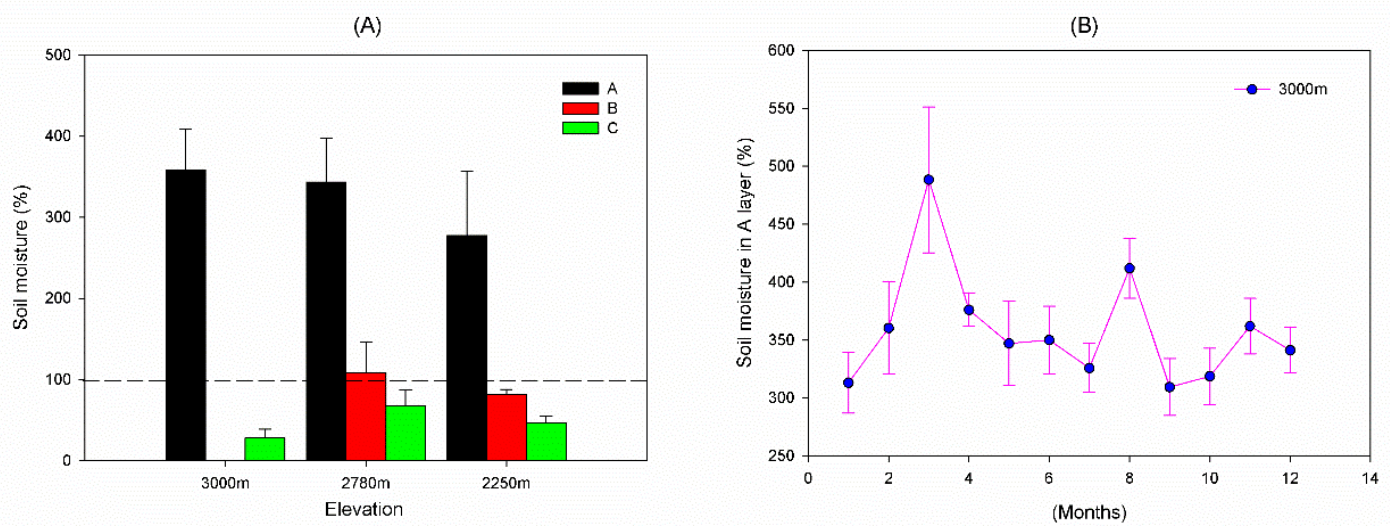

473

474 


\section{Figures}

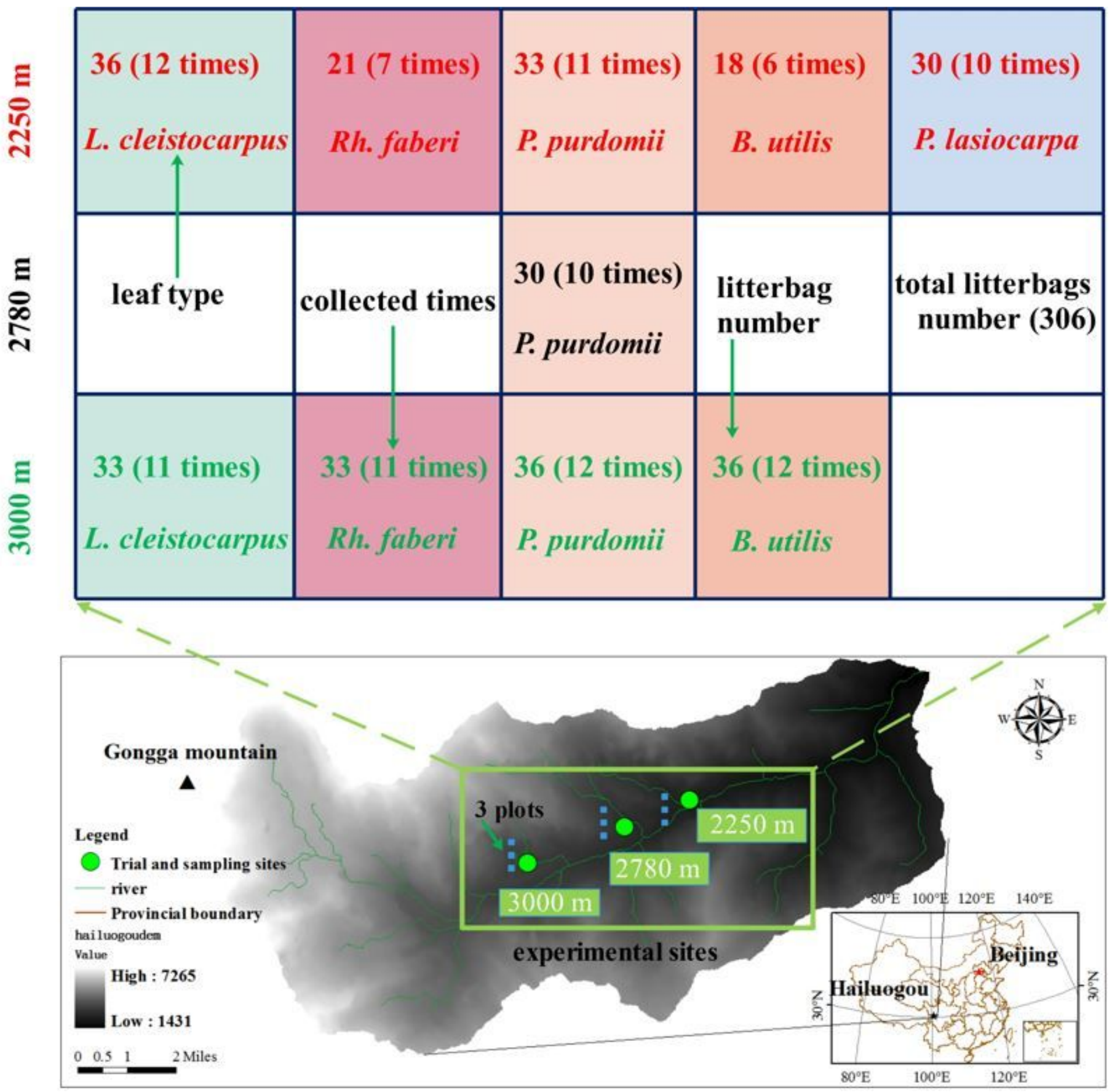

\section{Figure 1}

Experimental sites, leaf types, times and total number of all collected litterbags at the end of decomposition experiment. Note: The designations employed and the presentation of the material on this map do not imply the expression of any opinion whatsoever on the part of Research Square concerning the legal status of any country, territory, city or area or of its authorities, or concerning the delimitation of its frontiers or boundaries. This map has been provided by the authors. 

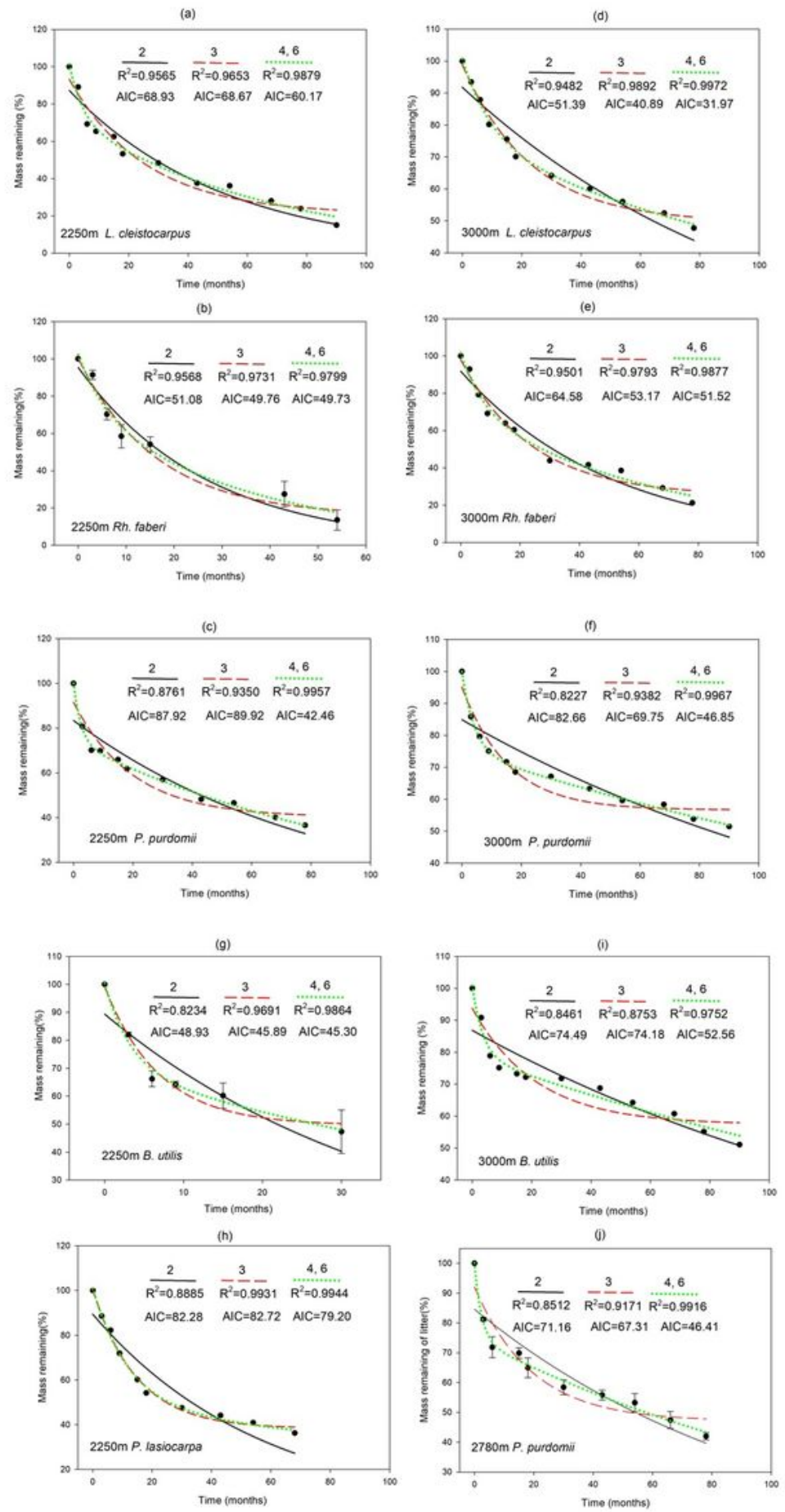

\section{Figure 2}

The comparison of different fitting models with respect to empiric litter decomposition rates col-lected at 2250, 2780 and $3000 \mathrm{~m}$ a.s.I. on the east slope of Gongga Mountain. Black solid line, red long-dash line and green dotted line were fitted by the two-, three- and four(six)- parameter models, respectively. The R2 and AIC value of each model was shown. 
(A)

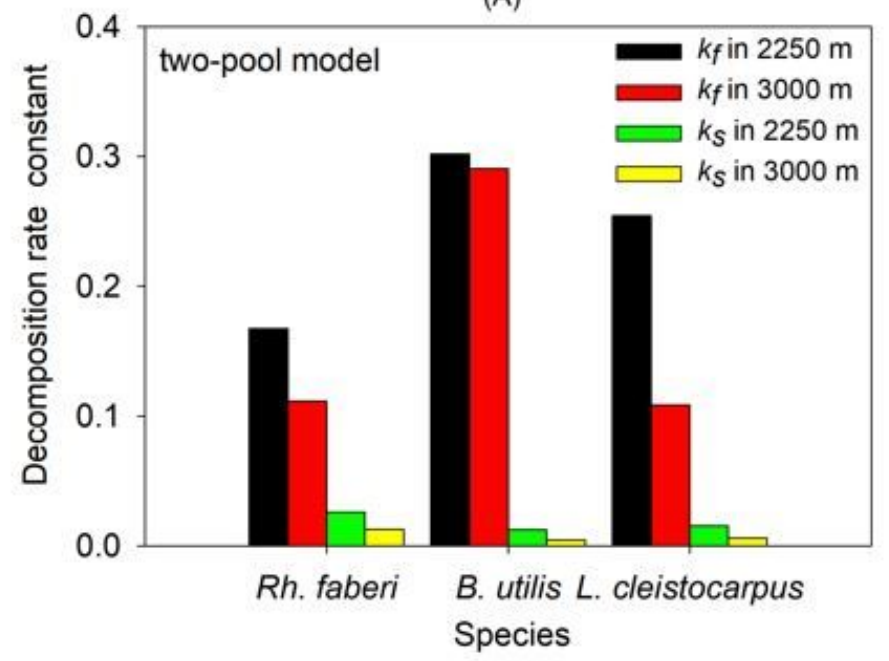

(B)

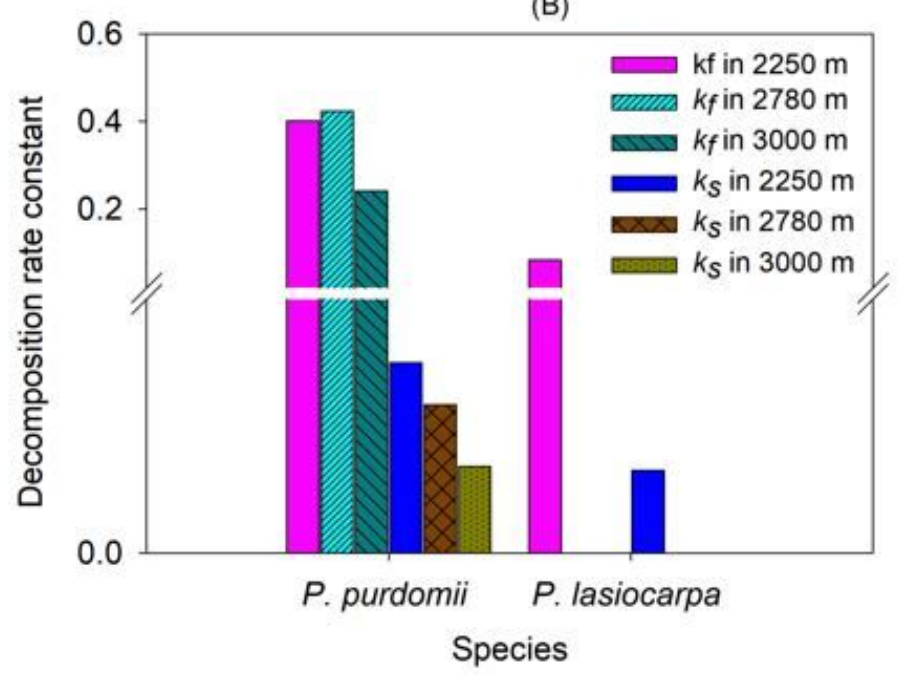

Figure 3

Comparison of decomposition rate constants in term of different species at different elevations based on the four-parameter model. The kf and ks stand for the fast and slow decomposition rate constant, respectively. 


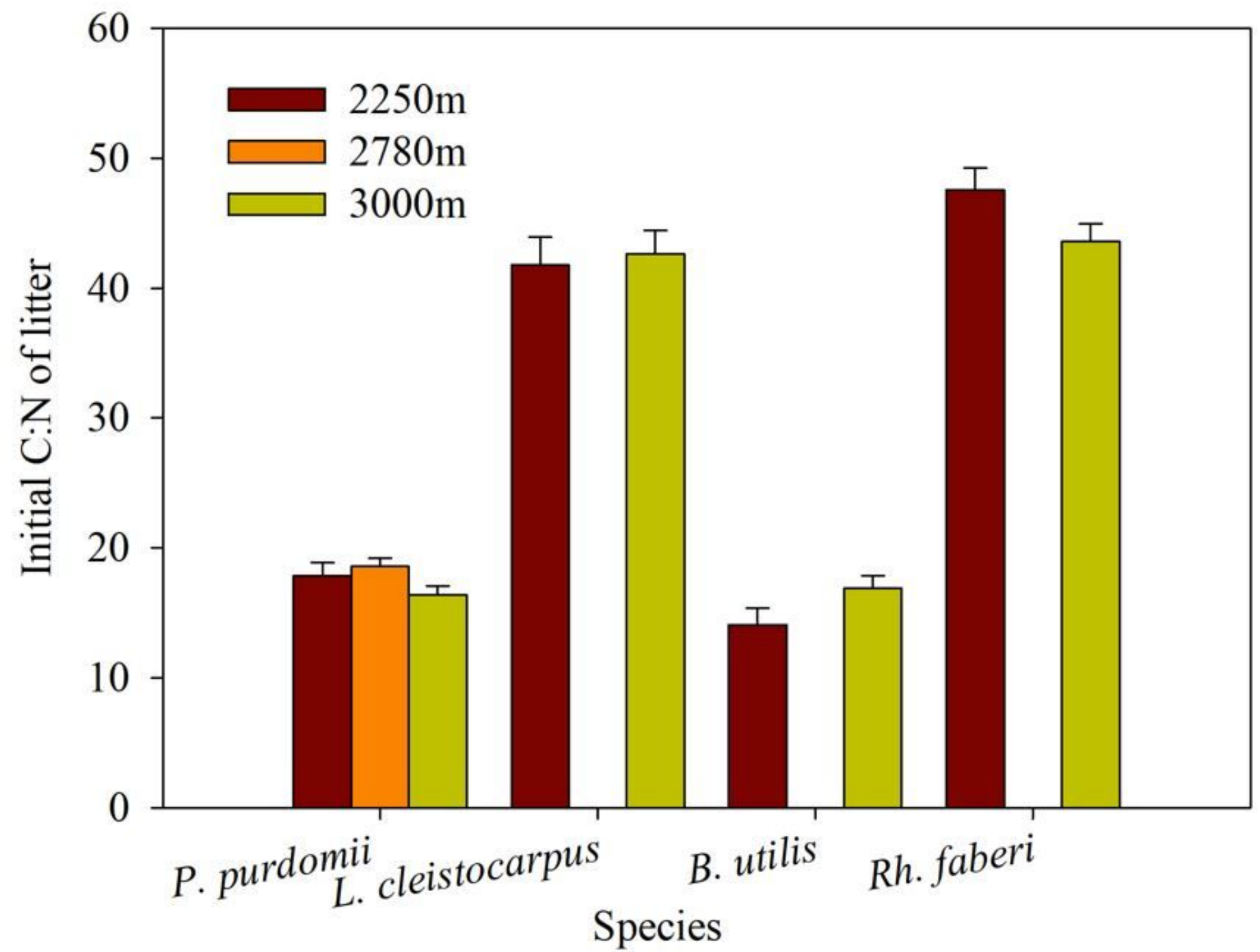

Figure 4

The initial C:N of litters (P. purdomii, L. cleistocarpus, B. utilis, Rh. faberi)

(A)

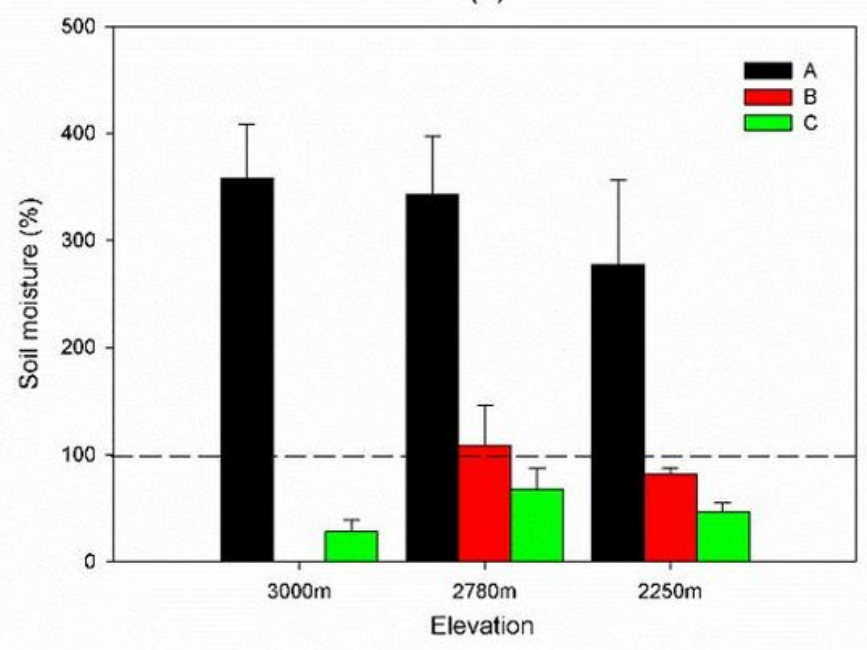

(B)

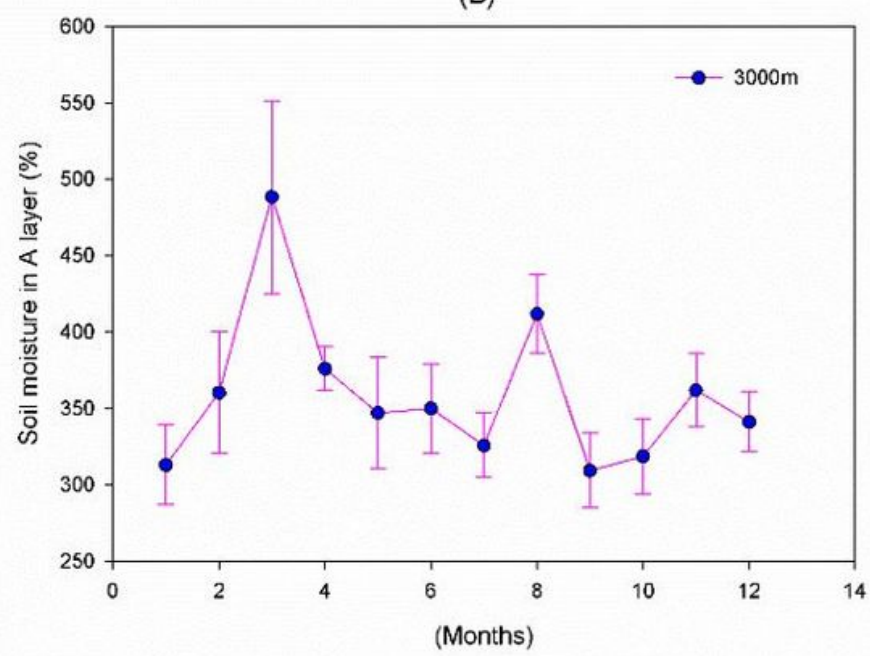


Figure 5

Plot A shows the soil moisture of different soil layer (A: 0-5 cm, B:5-10 cm, C:10-20 cm) in three elevations. Plot $B$ shows soil moisture with different months in A layer at $3000 \mathrm{~m}$ a.s.I..

\section{Supplementary Files}

This is a list of supplementary files associated with this preprint. Click to download.

- SupportingInformation.docx 